\title{
CONTROL DE CONVENCIONALIDAD Y DE CONSTITUCIONALIDAD EN EL ECUADOR
}

\author{
CONVENTIONALITY AND CONSTITUTIONALITY CONTROL IN ECUADOR
}

Karla A. Yánez-Yánez ${ }^{1}$

Frank L. Mila-Maldonado ${ }^{2}$

\section{Resumen}

El control de convencionalidad es un constructo teórico-jurisprudencial de la Corte IDH, que en términos generales busca la armonización del derecho interno respecto del derecho internacional de los derechos humanos. En este estudio, se pretende analizar dicha institución y su relación con el control de constitucionalidad. En ese sentido, se pretende dilucidar ¿Cuál es la relación entre el control de convencionalidad y el control de constitucionalidad?, para ello se utilizó el método dogmático jurídico, siendo una investigación documental. Se concluye que las instituciones se encuentran relacionadas en su carácter garantista de derechos humanos. Sin embargo, su fin jurídico es distinto puesto que una pretende la aplicación de los derechos humanos y la otra la supremacía constitucional.

\section{Palabras Clave}

Convención internacional, Derechos Humanos, Constitución, Ordenamiento jurídico, Control de Convencionalidad.

\begin{abstract}
Conventionality control is a theoretical-jurisprudential construct of the Inter-American Court, which in general terms seeks the harmonization of domestic law with respect to the IHRL. In this study, the aim is to analyze this institution and its relationship with constitutional control. In this sense, it is intended to elucidate what is the relationship between the control of conventionality and the control of constitutionality? For this, the dogmatic legal method was used, being a documentary investigation and as a conclusion, the institutions are related in relation to their However, its legal purpose is different, since one seeks the application of human rights and the other is constitutional supremacy.
\end{abstract}

\section{Key Words}

International Convention, Human Rights, Constitution, Legal order, Conventionality Control.

\footnotetext{
${ }^{1}$ Universidad de Otavalo. Correo electrónico: kyanez2253@gmail.com.

${ }^{2}$ Universidad de Otavalo. Correo electrónico: fmila@uotavalo.edu.ec.
} 


\section{Introducción}

La Convención Americana de Derechos Humanos (1969) ha sido suscrita por 24 Estados. Ecuador es uno de los países suscriptores del aludido instrumento desde el 22 de noviembre de 1969, y ha ratificado la competencia de la Corte Interamericana el 3 de agosto de 1984 (Ponce, 2005).

Ahora bien, la Corte Interamericana de Derechos Humanos, como órgano creado en la aludida convención, ha erigido una institución jurídica de reciente data, denominada control de convencionalidad, figura generada por la jurisprudencia de esta Corte, y que tiene como finalidad principal suprimir las normas del derecho interno que se opongan a los derechos tutelados por el Sistema Interamericano estatuido en la Convención Americana de Derechos Humanos (1969), así como armonizar los ordenamientos jurídicos de los Estados parte con lo establecido en la Convención.

En ese sentido, siendo que el control de convencionalidad debe aplicarse no solo por la Corte Interamericana de Derechos Humanos, sino que también por el propio Estado parte, en el caso que nos ocupa, Ecuador, por ello, se pretende dilucidar las semejanzas y diferencias de la institución mencionada con el control de constitucionalidad, puesto que, ambas instituciones tienen una finalidad semejante. De este modo, se analizará en primer lugar la jurisprudencia de la Corte Interamericana con la cual ha ido construyendo progresivamente el concepto del control de convencionalidad, a fin de determinar su contenido $y$ alcance, haciendo una referencia especial a si dentro de este control se incluyen las opiniones consultivas de la Corte Interamericana. Posteriormente se analizará el control de constitucionalidad, conforme a lo establecido en la Constitución de Montecristi (2008) y la dogmática constitucional, para generar conclusiones de la relación entre estas dos figuras jurídicas.

\section{Aproximación al concepto del Control de Convencionalidad}

La Corte Interamericana de Derechos Humanos (Corte Interamericana o CorteIDH), se ha referido en reiteradas ocasiones a las obligaciones de los Estados suscriptores de la Convención Americana sobre Derechos Humanos (Convención Americana, Convención o Pacto de San José), y al respecto plasmó en el Cuadernillo de Jurisprudencia $\mathrm{N}^{\circ} 7$ (2007), que:

Es consciente de que las autoridades internas están sujetas al imperio de la ley y, por ello, están obligadas a aplicar las disposiciones vigentes en el ordenamiento jurídico. Pero cuando un Estado es parte en un tratado internacional como la Convención Americana, todos sus órganos, incluidos sus jueces y demás órganos vinculados a la administración de justicia en todos los niveles, también están sometidos al tratado, lo cual les obliga a velar para que los efectos de las disposiciones de la Convención no se vean mermados por la aplicación de normas contrarias a su objeto y fin, de modo que decisiones judiciales o administrativas no hagan ilusorio el cumplimiento total o parcial de las obligaciones internacionales. (p.25)

En ese sentido, el control de convencionalidad ha sido definido por la Corte Interamericana de Derechos Humanos (2013) como una institución creada para aplicar el Derecho Internacional de los Derechos Humanos, el cual está conformado no solo por la Convención, sino por fuentes como la jurisprudencia de la Corte IDH.

Burgorgue-Larsen (2012) indica que este concepto se ha desenvuelto en tres tiempos: el primero fue la aparición del deber de control con el Caso Almonacid Arellano vs Chile en septiembre de 2006, en segundo lugar, el establecimiento de los contornos de esta obligación con el Caso Trabajadores Cesados del Congreso vs Perú en noviembre del mismo año, y por último la teorización del control con el caso Cabrera García y Montiel Flores vs. México en el 2010.

Asimismo, en palabras de Sagüés (2011), la Corte Interamericana describe a la institución del control de convencionalidad en tres aspectos: El primero de ellos referido al principio de la buena fe en el cumplimiento de las obligaciones internacionales por parte de los Estados suscriptores de la Convención Interamericana de Derechos Humanos, el segundo relacionado con el principio del efecto útil de los convenios, cuya eficacia no puede ser mermada por normas o prácticas de los Estados; y como tercer aspecto señala el principio internacionalista que impide alegar el Derecho Interno para eximirse de aquellos deberes.

\section{Formas de aplicación ¿Quién aplica? y tipos de Control de Convencionalidad ¿Sobre qué se aplica?}

En este aspecto, es menester destacar que la figura jurídica del control de convencionalidad no se limita a un control internacional de la aplicación de la convención. De igual manera puede ser visto desde una óptica o ámbito nacional, por ello, Sagüés (2011), apunta varios casos de 
la Corte Interamericana, en los cuales se materializan estos niveles, a saber:

El caso La última tentación de Cristo, reputó violatoria del Pacto a una cláusula de la Constitución de Chile en materia de censura televisiva y exigió su reforma, cosa que finalmente ocurrió. Asimismo, en el caso Boyce contra Barbados, la Corte entendió que también infringía el Pacto una regla constitucional de este país, que impedía el control judicial de las normas anteriores a la Constitución de 1996, aunque vulnerasen derechos fundamentales. A esta variable se le llama, control concentrado de convencionalidad o supranacional de convencionalidad, el cual, se constituye como la función por excelencia de la Corte Interamericana.

Entonces se puede indicar que, en definición, el control concentrado se trata de la competencia asignada a un tribunal internacional para determinar la responsabilidad internacional de los Estados partes cuando vulneran el derecho convencional a través de sus normas o actos (Neubaum, 2016).

Y por su parte, el control difuso es el que se ejerce por los Estados. Es el juez del Estado el que se encuentra obligado a ejercer este control, interpretando las normas internas conforme la Convención Americana y verificando su adecuación a esta última. (Neubaum, 2016)

Ahora bien, como se expresó, fue a partir de 2006 en Almonacid Arellano, que la Corte Interamericana va a reclamar a los jueces nacionales que inapliquen, ellos mismos, las normas locales opuestas al Pacto de San José de Costa Rica, y a su propia jurisprudencia. Tal es el segundo nivel del control de convencionalidad, y al que nos referiremos de aquí en adelante. Usualmente se la denomina control difuso de convencionalidad o control nacional de convencionalidad.

En resumidas cuentas, de acuerdo a lo desarrollado por la Corte Interamericana de Derechos Humanos, podemos inferir que existen dos formas de aplicación del control de convencionalidad relacionadas a la interrogante ¿Quién aplica?: La primera es el control concentrado de convencionalidad; la segunda es el control difuso de convencionalidad.

Estas dos formas de control, a su vez se dirigen a dos tipos de disposiciones de forma concreta o abstracta, los que responderá a la pregunta ¿Sobre qué se aplica?: el control concreto se realiza sobre normas o leyes que han sido aplicadas a casos particulares y en los que se considera existe una violación de derechos por la aplicación de la norma (Aguirre, 2016). En tanto que el control abstracto se realiza sobre normas o leyes que aún no han sido aplicadas a un caso concreto, pero que se considera vulneran derechos por su simple existencia. En este orden de ideas, es importante subrayar que tanto la Corte IDH, como las instancias internas de los Estados pueden ejecutar un control de convencionalidad concreto y abstracto.

Respecto de normas objeto de ser controladas por la institución de la convencionalidad apunta Sagüés (2011) que:

Hay normas controladas, conformadas por todo el derecho de cada país, formal o consuetudinario, incluyendo la Constitución. En Almonacid Arellano la Corte Interamericana señaló que el control de convencionalidad se practicaba sobrelas "leyes contrarias a su objeto y fines", pero en Trabajadores cesados del Congreso, mencionó como material controlado a las "normas jurídicas internas", sin diferenciar a las subconstitucionales o a las constitucionales. (p.389)

$\mathrm{Al}$ respecto, se concluye que en la actualidad todos los actos estatales, así como las normas legales, constitucionales y el ordenamiento jurídico en general, son susceptibles de contrastación con el Derecho Internacional de los Derechos Humanos y por tanto, de aplicar control de convencionalidad, sin embargo, es importante destacar que existe una excepción a la aplicación del control de convencionalidad en el caso ecuatoriano, y, será en los casos en los cuales la norma interna sea más protectora o garantista de derechos que la Convención sub examine, o la doctrina de la Corte, en virtud del principio pro homine, el cual implica que la norma más benigna prevalecerá de conformidad con el artículo 424 de la Constitución del Ecuador.

\section{Efectos de la aplicación del Control de Convencionalidad}

De lo expuesto, se infiere que el control de convencionalidad se realiza mediante la comparación de las normas del Estado parte frente a la Convención Americana, así como de la jurisprudencia de la Corte Interamericana. De ahí que todos los actos y actividades del Estado estén sometidos a este control, comenzando por la propia Constitución y las leyes, los actos administrativos, las sentencias y, en general, todos los demás actos estatales (Ayala cit.p. Segado, 2013).

Este proceso de constatación entre el derecho interno y el internacional de los Derechos Humanos, se realiza según Midón (2016), a través de algunas reglas básicas, entre las cuales destacan: 
- La ratificación de un tratado obliga al Estado a velar por su cumplimiento;

- Los jueces, como parte del aparato estatal, se encuentran sometidos a lo que disponen tales tratados;

- El Poder Judicial debe velar por la aplicación de los mismos y procurar su plena efectividad, y;

- Debe tenerse en cuenta, a tal efecto, no solo la letra del tratado sino también la jurisprudencia de la Corte Interamericana.

Asimismo, la Corte Interamericana en el año 2008, en el caso Heliodoro Portugal vs. Panamá, señaló que debe velarse por el efecto útil de los instrumentos internacionales, y que, por tanto, el derecho interno de cada Estado debe adecuarse a la Convención. Esta sentencia, marcó la pauta para los efectos del ejercicio del control de convencionalidad, derivándose en un efecto supresivo y otro preventivo.

En lo atinente al efecto supresivo de normas, este aplica cuando se determine la inconvencionalidad de alguna norma, en razón que represente una violación a las garantías o derechos previstos en el Pacto de San José o la jurisprudencia desarrollada por la Corte Interamericana -sentencias definitivas de casos contenciosos o de reparaciones, resoluciones interpretativas de sus fallos, medidas provisionales u opiniones consultivas-.

Por otra parte, el efecto preventivo se manifiesta en el proceso de creación legislativo de normas y actos administrativos y judiciales en general del Estado adecuados al Derecho Internacional de los Derechos Humanos.

\section{Opiniones consultivas de la Corte Interamericana de Derechos Humanos}

Una vez clara la definición del control de convencionalidad según la doctrina de la Corte Interamericana, es preciso inferir en detalle, en el alcance de esta institución, ya que representa la materialización de la fuerza vinculante no solo del Derecho Internacional de los Derechos Humanos, representado prima facie por la Convención Interamericana de Derechos Humanos y la jurisprudencia de la Corte Interamericana, sino también de las opiniones consultivas de la Corte Interamericana.
Las opiniones consultivas, son la respuesta de la Corte Interamericana ante una consulta elevada a su conocimiento por alguno de los Estados parte de la Convención Americana o por la Organización de los Estados Americanos, sobre algún aspecto en específico no judicializado o contencioso.

En ese aspecto, la Corte Interamericana se ha pronunciado sobre el valor interpretativo de las opiniones consultivas, $y$ ha determinado que:

(...) conforme al derecho internacional, cuando un Estado es parte de un tratado internacional, como la Convención Americana sobre Derechos Humanos, dicho tratado obliga a todos sus órganos, incluidos los poderes judicial y legislativo, por lo que la violación por parte de alguno de dichos órganos genera responsabilidad internacional para aquél. Es por tal razón que estima necesaria que los diversos órganos del Estado realicen el correspondiente control de convencionalidad para la protección de todos los derechos humanos, también sobre la base de lo que señale en ejercicio de su competencia consultiva, la que innegablemente comparte con su competencia contenciosa el propósito del sistema interamericano de derechos humanos, cual es, "la protección de los derechos fundamentales de los seres humanos (el énfasis es nuestro)." (Corte Constitucional del Ecuador, 2019a, párr.34)

En ese sentido, se observa que la función consultiva de la Corte, se equipara a su función contenciosa, ya que comparten el mismo fin, a saber: la protección y garantía de los Derechos Humanos, así como por el hecho se ser la Corte la máxima instancia de interpretación del Pacto de San José y por lo tanto, las opiniones consultivas -solicitadas por quien fuere- forman parte del denominado bloque de convencionalidad, y en ese sentido, son vinculantes para todos los Estados parte de la Convención Americana de Derechos Humanos.

\section{Corte Constitucional del Ecuador y juriprudencia sobre convencionalidad y constitucionalidad}

La Corte Constitucional del Ecuador, en su sentencia No 11-18-CN/19 (Corte Constitucional del Ecuador, 2019a) derivada de la consulta de una acción de protección de derechos humanos emitida por el Tribunal de la Sala Penal de la Corte Superior de Justicia de Pichincha, analiza el valor jurídico y el efecto vinculante de la Opinión Consultiva OC 24/17 de la Corte Interamericana de Derechos Humanos, que reconoce el matrimonio de parejas del mismo sexo, a la luz del control del control de 
convencionalidad.

Asimismo, en la Sentencia No 10-18-CN/19 (Corte Constitucional del Ecuador, 2019b) relativa a la consulta de constitucionalidad de los artículos 81 del Código Civil (2005) y 52 de la Ley Orgánica de Gestión de la Identidad y Datos Civiles (2016), analiza la constitucionalidad de las normativas señaladas, siendo que el artículo 67 de la Constitución del Ecuador (2008), establece que el matrimonio es entre hombre y mujer.

En ese sentido, en dichas sentencias la Corte Constitucional establece el valor jurídico que tienen los instrumentos internacionales de derechos humanos, tanto tratados como el resto de tipologías (pactos, convenciones, entre otros), resaltado que está claramente determinado en la Constitución, específicamente en el artículo 417 y 426 de la Constitución del Ecuador que disponen los principios pro ser humano, de no restricción de derechos, de aplicabilidad directa, cláusula abierta; así como el cumplimiento y la aplicación directa de los derechos constitucionales y humanos

Con lo cual concluye que, en Ecuador, la distinción que hace la doctrina internacional entre tratados $y$ otros instrumentos internacionales, para efectos del reconocimiento de derechos y desarrollo de su contenido, es irrelevante. Todos los derechos reconocidos en instrumentos internacionales forman parte del sistema jurídico ecuatoriano. (Corte Constitucional del Ecuador, 2019a,)

Por otra parte, al entrar al fondo de la controversia, se estableció claramente la contradicción entre la norma interna, a saber, el artículo 67 de la Constitución del Ecuador (2008), el artículo 81 del Código Civil (2005) y el artículo 52 de la Ley Orgánica de Gestión de la Identidad y Datos Civiles (2016), las cuales establecen en concordancia que el matrimonio es entre un hombre $y$ una mujer, $y$, por otra parte la norma convencional, la reciente Opinión Consultiva OC 24/17, la cual reconoce el matrimonio entre personas del mismo sexo.

En lo que respecta al control de convencionalidad, la Corte Constitucional se ciñe a lo dispuesto por la Corte Interamericana, adoptando los pronunciamientos de la misma, en los que señala las obligaciones derivadas del control de convencionalidad, resumidas en cuatro aspectos:

a) El control de constitucionalidad se complementa con el de convencionalidad y hay que hacerlas de oficio; b) el control de convencionalidad lo hacen las autoridades públicas en el marco de sus competencias; c) el control de convencionalidad es de tratados y de las interpretaciones de sus órganos; $y, d$ ) el control de convencionalidad también se aplica en las opiniones consultivas. (Corte Constitucional del Ecuador, 2019a, párr.267)

Además, es menester señalar que en anteriores ocasiones la Corte Constitucional ha reconocido el efecto vinculante de la doctrina de la Corte Interamericana, por ejemplo, en el renombrado caso Satya, en el cual se reconoció el derecho a la familia de una pareja homosexual.

Por otra parte, en cuanto al análisis de constitucionalidad realizado por la Corte Constitucional (2019b), de la normativa legal que regula la institución del matrimonio en primer lugar, hace referencia a la Constitución como la máxima jerarquía formal indicando que es "el documento autoritativo con mayor rigidez que el de la ley" (párr.23), pero que también posee un alcance sustantivo, compuesto por un "tejido de principios, fines y valores, de justicia, que goza de prioridad axiológica respecto de la ley, y que subyace al documento promulgado por la autoridad constituyente" (párr.23).

De lo señalado, se desprende que la Constitución, no solamente tiene mayor fuerza que la ley, sino que, además, en lo que respecta a la dimensión sustantiva, trasciende a la interpretación constitucional que debe darse a las normas de rango legal, así como a la Constitución en si misma, en virtud que está compuesta no solo por reglas sino por principios.

Por tal razón, no se debe limitar o circunscribir la interpretación de la Constitución al tenor literal de la misma, sino que debe trascender al plano de principios, puesto que aquellos se consideran por la doctrina como mandatos de optimización, en ese sentido apuntó la Corte (2019b) que ello, constituye la mayor debilidad de los argumentos literalista, puesto que dan un enfoque formalista a la interpretación constitucional, "eclipsando la dimensión sustantiva de la Constitución” (párr.31).

Asimismo, la Corte se apoya en el Derecho Internacional de los Derechos Humanos para su argumentación, analizando los casos relevantes de la Corte Interamericana, la Convención Americana sobre Derechos Humanos, así como los derechos fundamentales más favorables, concluyendo que:

Nuestra Constitución reconoce el derecho de las pajeras del mismo sexo a que el legislador instituya (esto es, haga posible y regule) para ellas el matrimonio, otorgándoles 
- con dicha institucionalización- el poder jurídico de casarse. Consiguientemente el legislador está obligado a hacerlo. (Corte Constitucional del Ecuador, 2019b, párr.91)

Y, en ese sentido, declara la inconstitucionalidad de las normas legales que regulan el matrimonio, por cuanto al interpretar la Constitución a la luz del Derecho Internacional de los Derechos Humanos, se infiere que los artículos objetos de debate vulneran derechos constitucionales como el derecho a la familia, en sus diversos tipos y el derecho a igualdad y no discriminación, entre otros.

De las sentencias analizadas, se desprende que ambas utilizaron dentro de su argumentación aspectos relativos al Derecho Internacional de los Derechos Humanos, sin embargo, una utilizó un enfoque convencional a través de la aplicación de una opinión consultiva y la otra constitucional, a través de una interpretación pro persona puesto que, ambas instituciones fungen de forma similar en cuanto a la búsqueda de garantizar y aplicar los derechos humanos.

\section{Relación entre el control de convencionalidad y control de constitucionalidad}

El control de constitucionalidad, el cual, nace en 1803 con la famosa sentencia del juez John Marshall, siendo el principio de supremacía constitucional es la fuente de su razonamiento, al otorgar la potestad a los jueces de realizar un control sobre las leyes inconstitucionales, de tal manera que "una ley contraria a la Constitución es nula y que los tribunales, además de los demás poderes, están sometidos a la Constitución" (Marbury vs Madison)

El Control de Constitucionalidad ya existía en el Ecuador con la Constitución de 1998, sin embargo, luego de la entrada en vigencia de la Constitución de 2008, en la cual se ha constituido como un Estado Constitucional de Derechos y Justicia, esta figura jurídica cobra vital importancia, puesto que al ser la Constitución un aspecto medular del Estado, el control de constitucionalidad de las leyes es una de sus expresiones más destacadas, en razón se constituye como una figura que viabiliza la efectiva materialización de los principios y reglas contenidos en la Constitución, puesto que, de lo contrario lo establecido en la constitución solo sería retorica.

Segado (2004), señala que la fuerza normativa de la constitución implica un paradigma sin el cual no podría hoy entenderse el constitucionalismo fuerte, donde los derechos fundamentales son garantizados y el control de la constitucionalidad de las leyes por los jueces cobra vital importancia, sea por cualquier juez en los sistemas difusos para la desaplicación de la norma al caso particular; o bien por el juez constitucional en los modelos concentrados, para declarar la invalidez de las normas con efectos generales -como lo es el caso actual del Ecuador-

Como se indicó, el control de constitucionalidad en el Ecuador es concentrado, puesto que es el órgano especializado y competente, a saber, la Corte Constitucional, quien declarara la inconstitucionalidad a través de la acción pública de inconstitucionalidad o la consulta de constitucionalidad. Este último, a través de consulta elevada por un juez respecto de una duda razonable y motivada.

Este control de constitucionalidad concentrado (en la Corte Constitucional del Ecuador) se equipará en cierto modo al control de convencionalidad difuso, que es una obligación que recae sobre los jueces nacionales de cada Estado, y para el caso ecuatoriano, de conformidad con la Constitución (2008) en su artículo 424 que dicha norma es suprema, y prevalece sobre cualquier otra del ordenamiento jurídico. Asimismo, hace mención a los tratados internacionales de derechos humanos ratificados por el Estado que reconozcan derechos más favorables, los cuales se aplicarán preferentemente sobre cualquier acto o disposición del Estado.

Es por ello, siguiendo a Ferrer (2012) los jueces de cada Estado, no deben limitarse únicamente a la aplicación de las leyes nacionales, sino que deben realizar interpretaciones convencionales, ello, con la finalidad de verificar que las leyes que aplicarán en un caso particular son compatibles con lo dispuesto en la Convención Americana, caso contrario generarían una vulneración de derechos y, por tanto, posterior responsabilidad internacional al Estado parte.

La propia Corte Interamericana de cierto modo ha asimilado las instituciones de control de convencionalidad con el control de constitucionalidad indicando que los órganos del Poder Judicial deben ejercer no sólo un control de constitucionalidad, sino también 'de convencionalidad' ex officio entre las normas locales y la Convención Americana, (Corte Interamericana, 2006), evidentemente en el marco de sus respectivas competencias y de las regulaciones procesales correspondientes.

Por lo tanto, ambas instituciones -control de constitucionalidad y control de convencionalidadaunque tengan una procedencia distinta, y ciertamente 
cada una se aplique con un fin jurídico distinto, a saber, la supremacía constitucional y la aplicación de los tratados y convenios internacionales, tienen un carácter protector y garantista de derechos, y buscan armonizar la normativa interna del estado a lo establecido en la constitución o convención en materia de derechos humanos, por tanto, no son excluyentes, sino complementarias entre sí, incluso se aduce que el control de convencionalidad se constituye en un control de constitucionalidad más amplio, y por tanto, los operadores de justicia deben incorporar al sistema las normas constitucionales, las convenciones, la jurisprudencia internacional y al mismo efecto las opiniones consultivas.

Asimismo, la aludida Corte Constitucional (2019a) arguye que la eficacia normativa de la Constitución tiene sentido cuando quienes interpretan y aplican normas jurídicas en su trabajo cotidiano, en particular los jueces y las juezas, pueden y deben aplicar la Constitución y los instrumentos internacionales de derechos humanos cuando son más favorables.

Es por ello, que tal como señala Gutiérrez (2011) la recepción del derecho internacional en cada Estado, tiene por efecto que los tratados internacionales formen parte del ordenamiento jurídico interno, pasando de un estatus legal a supra legal o constitucional como lo es en el caso del Ecuador.

En ese sentido, la tesis defendida en esta investigación radica en que los operadores de justicia tienen competencia por medio del control de convencionalidad o de constitucionalidad, de aplicar en los casos concretos la Convención o Constitución, en los casos que se trate, en los cuales se vulneren derechos de esta índole, con el fin proteger y garantizar los derechos humanos y constitucionales, ya que es esta es una facultad de la cual están investidos, sin embargo, no deben confundirse estas instituciones, puesto que formalmente poseen características que les diferencian aunque pudiesen generar resultados similares.

Esto delimita la importancia de las instituciones de la convencionalidad y constitucionalidad, en virtud que como señalamos anteriormente, respecto de la convencionalidad, tienen efecto supresor, pero también preventivo.

Por tal razón, se concuerda con lo sostenido por Gutiérrez (2016), quien indica que el control de convencionalidad y el control de constitucionalidad tienen un parámetro de control diferente y un objetivo o finalidad propia. Mientras el primero busca asegurar la primacía convencional, el segundo se encarga de hacer realidad la supremacía constitucional.

Es por ello que la Corte Constitucional del Ecuador, en sus recientes jurisprudencias, ha adecuado el ordenamiento jurídico legal ecuatoriano a la constitución y a la convención americana, es decir, desde la constitucionalidad y convencionalidad, por lo cual, se concluye que ambas instituciones son herramientas útiles y eficaces, para la materialización de derechos y garantías fundamentales y de derechos humanos, y por tanto deben ser utilizadas por los operadores de justicia en todos sus niveles.

Como se pudo observar, en la sentencia 11-18-CN/19, se da una argumentación desde la convencionalidad, los derechos humanos y las obligaciones de los Estados parte del Sistema Interamericano de Protección de los Derechos Humanos, al considerar que, las opiniones consultivas son parte de la jurisprudencia de la Corte Interamericana como máximo órgano interpretativo de la Convención Americana, y que en tal sentido son vinculantes para el Ecuador aun cuando éste último no hubiese sido el Estado solicitante.

Por otra parte, en la sentencia 10-18-CN/19, el análisis es desde la óptica constitucional, al considerar que la Constitución del Ecuador al no prohibir expresamente el matrimonio entre personas del mismo sexo, por el contrario, lo reconoce, y materializado la institución del control de constitucionalidad, declara la inconstitucionalidad de las normas legales.

En tal sentido, sostenidas las anteriores consideraciones, esta investigación propone un aporte a la teoría del derecho, en virtud que la definición del control de convencionalidad y sus puntos de encuentro con el control de constitucionalidad se encuentran en vías de desarrollo por la doctrina, ya que pese a la basta jurisprudencia de la Corte Interamericana, aún existen aspectos por estudiar a profundidad, sin embargo, se trata de una institución que ya ha sido aplicada en el Ecuador en casos relevantes, como los analizados, lo cual pone de manifiesto la relevancia y actualidad de dichas instituciones en el marco del Derecho Constitucional.

\section{Conclusiones}

El control de convencionalidad, es una institución creada mediante la jurisprudencia de la Corte Interamericana de Derechos Humanos, reiterada en el tiempo en más de una docena de sentencias de casos contenciosos, así como en sus opiniones consultivas.

En lo que respecta a su ejercicio, tiene una doble 
dimensión, en primer lugar, puede ser aplicado de forma concentrada, en este caso, la Corte Interamericana y en segundo lugar de forma difusa por los jueces nacionales del Estado parte que se trate.

En cuanto a los efectos del control de convencionalidad, se observan dos: el primero, un efecto supresor de normas o actos internos que vulneren los derechos tutelados por el Sistema Interamericano (Control concreto) y el segundo, un efecto de prevención (Control abstracto), en tanto los órganos nacionales y el derecho interno actúen de conformidad con el mismo. A través de los efectos del control de convencionalidad, pudiese llegar a crearse un derecho internacional a la región interamericana en cuando a Derechos Humanos, en tanto los Estados parte de la Convención tengan la voluntad de dar seguimiento a la doctrina internacional dentro de sus actos legislativos y judiciales.

Ecuador, desde la Constitución de 2008, acoge a las normas de derecho internacional dentro del sistema jurídico, y les otorga jerarquía infraconstitucional, pero supra legal, con lo cual son de directa aplicación en el país, y en caso de conflicto se decanta por el principio pro homine favoreciendo a la norma que favorezca a los derechos humanos.

La Corte Constitucional del Ecuador, en su jurisprudencia otorga fuerza vinculante a las opiniones consultivas de la Corte Interamericana, y por tanto pasan a formar parte del bloque de constitucionalidad.

El control de constitucionalidad en el Ecuador es concentrado (Corte Constitucional), sin embargo, en virtud del principio de aplicación directa de los derechos constitucionales y humanos, todos los funcionarios administrativos y judiciales tienen el deber de adecuar sus actuaciones en ese sentido. La Constitución ecuatoriana reconoce a los tratados y convenios internacionales con jerarquía constitucional y por tanto la Constitución y el Derecho Internacional de los Derechos Humanos deben complementarse y, en caso de colisión entre aquellos aplicarse el más favorable a la persona, y en ese sentido adecuar las normas infra constitucionales a lo dispuesto en dichos instrumentos.

Las instituciones del control de convencionalidad difuso y el control de constitucionalidad, no son excluyentes entre sí, se complementan, en el sentido que ambas pueden y deben ser aplicadas por los jueces de cada Estado parte, y de forma oficiosa, ello, para evitar futuras responsabilidades internacionales al Estado ecuatoriano. Sin embargo, tienen un parámetro de control diferente, el primero busca aplicar las normas convencionales y el segundo se encarga de materializar la supremacía constitucional. Sin embargo, su objetivo es unísono, la garantía y protección de los derechos humanos.

\section{Referencias}

1. Aguirre Castro, PJ. (2016). El control de convencionalidad y sus desafíos en Ecuador. Revista IIDH, 64, 265-310.

2. Burgorgue-Larsen, L. (2012). La erradicación de la impunidad. Claves para descifrar la política jurisprudencial de la Corte Interamericana de Derechos Humanos. En: Eduardo FerreroMac-Gregor (coord.). El control difuso de convencionalidad. Diálogo entre la Corte Interamericana de Derechos Humanos y los jueces nacionales. México: Fundap.

3. Código Civil (2005). Registro Oficial Suplemento 46 de 24 de junio de 2005 Última modificación: 22 de mayo de 2016. Ecuador.

4. Constitución de la República del Ecuador (2008). Registro Oficial número 449 de fecha 20 de octubre de 2008. Ecuador.

5. Convención Americana sobre Derechos Humanos (1969). Conferencia Especializada Interamericana de Derechos Humanos, 22 de noviembre de 1969. San José de Costa Rica.

6. Corte Interamericana de Derechos Humanos (26 de septiembre de 2006). Fondo y reparaciones, Almonacid Arellano y otros c. Chile.

7. Corte Interamericana de Derechos Humanos (24 de noviembre de 2006). Fondo y reparaciones, Trabajadores Cesados del Congreso (Aguado Alfaro y otros) c. Perú.

8. Corte Interamericana de Derechos Humanos (2007). Control De Convencionalidad. Cuadernillo de Jurisprudencia de la Corte Interamericana de Derechos Humanos № 7.

9. Corte Interamericana de Derechos Humanos (12 de agosto de 2008). Excepciones Preliminares, Fondo, Reparaciones y Costas, Caso Heliodoro Portugal vs. Panamá. 
10. Corte Interamericana de Derechos Humanos (26 de noviembre de 2010) Excepciones preliminares, fondo y reparaciones, Cabrera García y Montiel Flores c. México.

11. Corte Interamericana de Derechos Humanos (20 de marzo de 2013). Gelman vs. Uruguay. Supervisión de cumplimiento de sentencia de la Corte Interamericana de Derechos Humanos.

12. Corte Interamericana de Derechos Humanos (2018). ABC de la Corte Interamericana de Derechos Humanos: El qué, cómo, cuándo, dónde y porqué de la Corte Interamericana. San José de Costa Rica.

13. Corte Interamericana de Derechos Humanos (24 de noviembre de 2017). Opinión Consultiva OC24/17 solicitada por la República de Costa Rica.

14. Corte Constitucional del Ecuador (12 de junio de 2019a). Sentencia 11-18-CN/19 [MP Ramiro Ávila Santamaría]

15. Corte Constitucional del Ecuador (12 de junio de 2019b). Sentencia 10-18-CN/19 [MP Alí Lozada Prado]

16. Ferrajoli, L., (2001). Los fundamentos de los derechos fundamentales. Madrid. Editorial Trotta.

17. Ferrer, E. (2012). Interpretación conforme y control difuso de convencionalidad. El nuevo paradigma para el juez mexicano. En: Carbonell, Miguel y Salazar, Pedro (coords.). La reforma constitucional en materia de derechos humanos: un nuevo paradigma. México: Porrúa-UNAM.

18. Gutiérrez, L. (2011). Control de constitucionalidad y control de convencionalidad interacción, confusión y autonomía. Reflexiones desde la experiencia francesa. Revista IIDH - Instituto Interamericano de Derechos Humanos, 64, 239-264.

19. Ley Orgánica de Gestión de la Identidad y Datos Civiles (2016) Registro Oficial Suplemento 684 de 04 de febrero de 2016.

20. Midón, M. (2016). Control de Convencionalidad. Buenos Aires. Editorial Astrea.
21. Molina, C. y Carrillo, Y. (2018). El matrimonio de parejas del mismo sexo y la Corte Constitucional de Colombia. Bogotá. Revista de Derecho, 31(1), 79103.

22. Neubaum, B. (2016). El diálogo interjurisdiccional entre la corte interamericana y la corte suprema de la nación argentina. El control de convencionalidad y la interpretación conforme. Revista Electrónica Cátedra Jean Monnet. Universidad de Buenos Aires Facultad de Derecho, 4(2), 45-71.

23. Ponce, A. (2005). El Ecuador y el Sistema Interamericano de Protección a los Derechos Humanos: una mirada crítica a la conducta estatal. Iuris Dictio. Revista del Colegio de Jurisprudencia Universidad San Francisco de Quito, 9, 15-22.

24. Sagüés, N. (2011). El "control de convencionalidad" en el sistema interamericano, $y$ sus anticipos en el ámbito de los derechos económico-sociales. Concordancias y diferencias con el sistema europeo. Construcción y papel de los derechos sociales fundamentales: Hacia un Ius Constitutionale Commune en América Latina. México: Universidad Nacional Autónoma de México: Max-PlanckInstitut für Ausländisches, Öffentliches Recht und Völkerrecht: Instituto Iberoamericano de Derecho Constitucional. pp. 381-41.

25. Segado, F. (2013). Carlos Ayala Corao: Del diálogo jurisprudencial al control de convencionalidad. Anuario Iberoamericano de Justicia Constitucional. Madrid. 17. pp. 665-728. 